\title{
An Inclusive and Sustainable Artificial Intelligence Strategy for Europe Based on Human Rights
}

Celia Fernández-Aller

Arturo Fernández de Velasco

Ángeles Manjarrés

David Pastor-Escuredo
Simon Pickin

Jesús Salgado Criado

Txetxu Ausín
The United Nations (UN) 2030 Agenda and other movements toward setting global goals such as the Paris Agreement and the European Green Deal/ U.S. Green New Deal are laying the groundwork for a transformation beyond purely market-based economics toward sustainability and inclusiveness [1], in which technological innovation and, in particular, artificial intelligence (AI) can play a central role. The European Union (EU) is committed to the 2030 Agenda and the sustainable development goals (SDGs), which the UN itself has recognized cannot be achieved without a people-focused, science-based, digital revolution [2]. This commitment to the 2030 Agenda should entail promoting an inclusive and sustainable AI strategy, rather than a strategy with a narrow focus on competitiveness [3] , [4]. In order for AI to contribute to achieving the SDGs, a systemic approach to the development of AI solutions is required [5]-[9]. Conversely, the SDGs provide an ideal framework to test the desirability of Al solutions [10]. Europe's multicultural character and its framework of international collaboration give it a head start toward becoming a global reference in the promotion of an inclusive and sustainable Al. Sharing the experiences and practices of such a European AI could make a significant contribution to achieving the SDGs.

A business- and competition-oriented view of $\mathrm{AI}$ is reductionist in human, social, and technological terms, losing sight of the object of technology as a tool to improve universal well-being, empowering the populace and enabling them to live more creative and satisfying lives. The instrumentalization of AI to optimize business objectives will likely lead 
to dystopic scenarios based on control and surveillance [11]. The competition-oriented view is also scientifically reductionist, in that actions and policies tend to techno-optimism and technological "solutionism" rather than being informed by deep and integrative research on issues such as avoiding "bias-by-design."

Inclusiveness is a key element of a humanbased AI, being also the motivation of the data revolution for sustainable development promoted by the UN in [3]. AI should help empower vulnerable groups, of which Europe also has its share, rather than contribute to marginalizing them. There is a significant risk of $\mathrm{AI}$ increasing socioeconomic disparities, notably by extending the existing digital divide into an AI divide (e.g., built-in social biases increasing discrimination against minorities, infrastructure poverty creating competitive disadvantages) [12], [13]; a competition-oriented Al strategy will make this risk more acute and will likely also have severe negative effects on the environment [10]. Universalizing the benefits of $\mathrm{Al}$ requires a strategy in which openness, in the sense of the upcoming United Nations Educational, Scientific and Cultural Organization (UNESCO) Open Science Recommendation [14] (open source, open data, open algorithms, etc.), can play an important role as an enabling factor, in particular, facilitating dissemination and auditing.

In the last few years, multiple ethical codes and guidelines for AI development and deployment have been drawn up by many different organizations, mostly in response to growing awareness of possible adverse effects of $\mathrm{AI}$. However, the resulting fragmented and largely corporate-based mosaic of ethical frameworks, codes, and guidelines, many of which suffer from deficiencies such a lack of scientific rigor, subjectiveness, incoherence, superficiality, and redundance, creates confusion [15], [16]. Moreover, the dominant reductionist vision promotes accountability for a number of commitments to technological principles, such as transparency, but not to upholding values, such as equity [17], [18]. Policy documents related to ethics and AI have also focused more on ethical frameworks than on possibilities for enhanced regulation [19]. However, there is a perceived need for new regulatory frameworks to reinforce the recommendations of policy documents, rather than relying on self-regulation and individual commitments, as has so far been the case ${ }^{1}$ purportedly due to fears that regulatory intervention could limit potential innovative capacity. The objective of an inclusive, sustainable, and human-centered AI in Europe will likely require a normative framework at the European level. Financial and regulatory stimuli are required to foster SDG-driven AI and public-private collaboration in the sharing of technology and data [22].

Furthermore, a human-centered AI should be human rights-based [23]. Although there has been some limited discussion at the European government level of the impact of $\mathrm{Al}$ on human rights, especially regarding the right to privacy, the impact on social, economic, and cultural rights has so far received little attention.

Data quality is of particular importance for $\mathrm{AI}$ applications, dictating the need for mechanisms and metrics to safeguard this quality, especially to ensure that training data does not result in bias. Open access to public-sector data sources with high scientific and social value is one way of contributing to reducing such bias. Ensuring the use of quality data also needs to address the thorny issue of public and third sector access to any private-sector data that is of vital or significant public interest. Increasing and optimizing access to, and usage of, data inevitably involves the interconnection of diverse data sources, bringing to the fore issues of privacy and security, which need further investigation.

Reliable and trustworthy AI understood in merely technical terms is not sufficient. The evaluation of impact, grounded in both the analytical and the social sciences, is essential to a human-rights-based approach [24]. Experimentation of AI systems at different scales prior to deployment is of great importance, and impact monitoring of such systems after deployment is crucial [16]. More (reproducible) research is needed on impact indicators for $\mathrm{Al}$ systems [25], on the validation and certification of properties such as explainability and algorithmic justice and on the development of applied-ethics

\footnotetext{
${ }^{1}$ Businesses should provide remediation for any adverse human rights impacts caused by Al through legitimate mechanisms. Although the International Law of Human Rights establishes the duty of the state to provide effective remedies through judicial and other mechanisms to those who have suffered business-related human rights abuses, it rarely happens. The UN Guiding Principles on Business and Human Rights can help, as they can clarify how preexisting international human rights standards apply to business activities, and provide useful guidance on how businesses can operate in a rights-respecting manner [20], Why Embracing Human Rights Will Ensure AI Works for All [21].
} 
tools, in general. This research should involve multidisciplinary teams that understand the technical, human, and social implications of $\mathrm{Al}$ algorithms and platforms [26].

Finally, ensuring that Al benefits society as a whole requires overcoming ethnocentric and androcentric approaches, opening dialogue mechanisms among different social actors, involving civil society in the discussions, and obligating a concomitant investment in $\mathrm{Al}$ education and literacy.

We need to go beyond an AI framework that is restrictive, reductionist and self-regulated, and work toward a future in which not only citizens are protected against the risks of AI, but also AI empowers and makes a decisive contribution to bringing peace, prosperity, and justice as well as to enhancing social, material, and spiritual well-being.

\section{Artificial intelligence and the Agenda 2030}

We believe that the position expressed in the 2020 European Commission (EC) White Paper on AI is technologically reductionist, in contradiction with the European commitment to the UN Agenda 2030, which is not given its due centrality and, indeed, is hardly mentioned. There is also an under-representation of the importance of human rights when analyzing $\mathrm{AI}$ impacts. Public policies on $\mathrm{Al}$ appear to be exclusively designed to improve the competitiveness of European companies in $\mathrm{AI}$ when the focus should be more on how AI helps to improve people's living conditions, contributes to the SDGs, and to the fight against climate change and its consequences.

In terms of specific content on the SDGs, the document makes only a timid mention of environmental sustainability, which did not figure as a significant issue in the accompanying public consultation questionnaire either. The potential and compelling purpose of technology to advance issues of rights, sustainability of communities, common welfare, and social and gender equality is ignored. In addition, the current crisis has highlighted the need to use $\mathrm{AI}$ to improve the health response at national and European levels, monitor progress of the infection, and mitigate our vulnerability.

The section of the document titled "Focusing the Efforts of the Research and Innovation Community" fails to mention promoting lines of research that support the SDGs, including the most pressing ones for Europe (fair and equitable data, sustainable economic development, risk prevention, and disaster management). This omission occurs in spite of the fact that the EU has also stated its commitment to the SDGs in the objectives of Horizon Europe and in the EU Framework Programme for Research and Innovation 2021-2027. The UN recognizes that the so-called digital revolution is a key enabler of sustainable development. It is also pertinent to observe that $\mathrm{Al}$ research and development in the field of SDGs is biased toward issues relevant to the nations where most researchers and practitioners live. There are very few AI technologies applied in less-developed countries where there is not a strong Al research base.

We believe it would advance the commitment to the 2030 Agenda if $\mathrm{AI}$ were developed with the philosophy of responsible research and innovation (RRI), which aims for a new model of research governance that reduces the gap between the scientific community and society, encouraging different stakeholders (educational community, scientific, business, industry, civil society organizations, and politics) to work together throughout the process of research and innovation. The idea is that cooperation between different (relatively autonomous but highly interdependent) actors will make it possible to align the research process and its results with society's values, needs, and expectations. Although the term RRI was coined a decade ago, it has recently gained prominence due to its inclusion in the Science with and for Society Programme promoted by the EC within the framework of the Horizon 2020 research strategy.

The RRI is a radical move toward openness and socialization of technoscientific processes that are embodied in four principles of governance: 1) anticipation; 2) reflexivity; 3) deliberation; and 4) accountability. The public engagement in research and innovation that RRI entails should lead to more ethical solutions to difficult problems, facilitating public acceptance and trust.

Another aspect that is missing from the document concerns the social and ethical impacts of AI. As AI permeates into more and more areas of society, it should increasingly be able to measure its own impact: AI should be self-assessing. Clear metrics are needed in this regard to avoid bias and undesired indirect impacts. Social and ethical impact assessment needs dedicated research and common tools (ethical and technological), without which impact 
is beyond the capability of most private companies. Furthermore, fragmented development of $\mathrm{AI}$ impact assessment by many different companies could increase biases and, at the same time, be a drain on resources of smaller companies, making them uncompetitive against the platforms of the digital giants [27].

\section{Avoiding ethnocentricity and androcentricity}

Although the need to avoid ethnic and gender discrimination and biases in Data Science projects is mentioned in the document (guaranteeing the representation of all groups in the data), there is no mention of the need to design applications adapted to different cultural sensitivities and values (culture-aware systems, see [28]) or the need to enhance the representation of all groups in the research, design, and development of Al applications (through mechanisms such as community-based development methodologies, citizen science, etc.). We emphasize the multicultural strength of Europe and the opportunity that this represents for $\mathrm{AI}$, as well as the synergies that can exist to build a more cohesive Europe if an AI sensitive to people and to these cultures is developed. This is only possible with the strengthening of pan-European research involving both the public and private sectors.

The document does speak of the need to promote women's vocations in AI technologies, but not to encourage female entrepreneurship in $\mathrm{AI}$. In the computer industry, only $1 \%-2 \%$ of new companies receiving venture capital funds are run by women, even though women-led companies get a $200 \%$ return on investment [29]. This is the area where gender biases in the technology industry are most apparent. This is a missed opportunity to develop a more inclusive and innovative AI.

\section{Universalizing the benefits}

The White Paper should position itself with respect to "open science," in the sense of the upcoming UNESCO Open Science Recommendation [30], or "open $\mathrm{Al}$ " paradigm (in particular, open source and open algorithms to facilitate the dissemination of the benefits of $\mathrm{AI}$ ). A paradigm of knowledge sharing, replicability, and openness is needed. Technology is not always neutral (see [31] and [32]) and design much less so (see [33]), and, furthermore, the adoption of $\mathrm{AI}$ is not within the reach of all.
For these reasons, AI will not diminish inequalities on its own unless specific policy lines are developed with these objectives in mind, along with the frameworks for ethical design, implementation, and impact assessment needed to support them. There is a risk of $\mathrm{AI}$ creating new inequalities as well as greater difficulties in the process of improving opportunities for vulnerable groups, thus creating an additional barrier between those who can benefit from $\mathrm{Al}$ and those who cannot. The risk is of creating a new AI gap, which would overlap with the already worrying digital divide that exists globally today. It would also be highly desirable to mention the promotion of a social economy in the AI sector.

\section{Education and digital literacy}

In our opinion, more emphasis should be placed on the need for multidisciplinary education in $\mathrm{AI}$, for raising the ethical and social awareness of Al professionals and researchers and for the education of society, in general, regarding digitization and $\mathrm{AI}$, one important reason being to raise awareness of its ethical and sociopolitical implications.

As recognized in several recent reports such as [34], ethics should be embedded in the engineering professional practice and education, providing students and engineers with the tools necessary to build an ethical orientation into their inventions. Therefore, regarding skills, educational institutions (especially universities) have a responsibility to provide curricula with the necessary multidisciplinarity, including a strong ethics-education component that incorporates philosophical, social, political, psychological, and risk analysis aspects of the development and implementation of AI technologies. Pedagogical research in these aspects should be promoted within the EU AI strategy.

\section{Dialogue between all social actors}

Dialogue between government and industry about the use of $\mathrm{Al}$ technologies is welcome but insufficient; any such dialogue should also involve the different social actors (third sector, civil society, academia,.etc.). To facilitate participation, it is essential that this dialogue be carried out in a transparent fashion, particularly as far as defining a regulatory framework for $\mathrm{AI}$ is concerned. The social value of $\mathrm{Al}$ is determined collectively; the wider the participation, the greater the confidence in, and the social appropriation of, the technology. 
The secondary role to which the document relegates participation of the wider society, both in $\mathrm{AI}$ development policies and in the $\mathrm{AI}$ regulatory efforts, is disturbing.

\section{$R \& D$ in ethical Al}

The EU AI development strategy should seek to promote independent and scientifically rigorous research in the ethical aspects of $\mathrm{AI}$ applications, both theoretical and practical/empirical perspectives, from philosophical reflection to the development of risk-mitigation strategies, impact assessment frameworks, and applied ethics method and tools. Such methods and tools are not meant to replace ethics legislation and good practice manuals, but rather to support their implementation. Both for the development of impact assessment frameworks and for that of the applied ethics methods and tools, a multidisciplinary approach is key to their utility.

The SDGs themselves define the basis of an impact assessment framework, defining indicators that cover multiple perspectives, including social costs and benefits, which can take into consideration the cultural values of the communities concerned.

Theoretical and empirical research on ethical AI lags far behind purely technological AI research, for which reason, the former should be given strategic priority over the latter. It is imperative to accelerate the development of AI ethical assessment frameworks to guide the future of $\mathrm{AI}$ in Europe. A commitment from the private sector is required to prioritize the assessment of algorithms and platforms.

\section{Encouraging multiscale experimentation}

Support tools for the application of ethical principles developed in research laboratories are currently at an early state of research so that their usefulness and impact are yet to be demonstrated. Examples of quantified good practice in the application of applied-ethics tools in real-world projects are needed. The promotion of R\&D projects for the experimentation of $\mathrm{Al}$ with an ethical approach involving industry, the public sector, and research centers, would help create such good practices.

Applied ethics tools also exist in the private sector and are used in internal consultancy. In general, these tools are in a very immature state and are not ready to be adopted by professionals in the short term, although in some very specific fields, effective tools with limited scope may already have been developed. Moreover, for the time being, using such tools does not provide any competitive advantage, which is why it is important to encourage them through proactive policies that promote their incorporation into business models. For impartiality, Al ethics assessment should be outsourced in the same way that many assessment, certification, and quality control processes are outsourced. For the assessment process to be homogeneous requires standards at national and European levels to guide and regulate the assessment tasks.

\section{Conflicts between $\mathrm{Al}$ and human rights protection}

The document refers to the defense of human rights, but only develops the arguments with regard to civil and political rights (privacy, political rights, and freedoms), ignoring social, economic, and cultural rights. This is closely related to concerns about the inequality that the massive use of AI could generate.

To prevent Al-based technological developments from causing human rights violations, the system of accountability needs to be restructured.

On many occasions, the end user is assigned the responsibility of verifying the guarantees of noninfringement of rights such as data privacy. However, the user lacks the capacity and vision to analyze complex systems. It is, therefore, necessary to create environments for public debate, where dialogues are held between researchers, developers, and members of civil society, as stated in the Zaragoza Declaration [35].

Assuming the need for transparent governance of $\mathrm{Al}$, the areas of $\mathrm{AI}$ research to be prioritized should include research on verifying the fairness of algorithms, with a view to integrating such verification mechanisms in a certification process to be carried out by an independent authority.

Quintanilla [36] coined the term "endearing technologies," as opposed to "alienating technologies"; this idea being consistent with the responsible research paradigm. We believe that such technologies are more respectful of fundamental rights. Some of their characteristics, as defined by Quintanilla, are: openness (the software is free); versatility (it allows alternative uses); docility (its operation and control depends on a human operator); no planned obsolescence (repair is promoted more than replacement); 
and comprehensibility (basic but comprehensive documentation).

\section{Public data infrastructures}

The deployment of Al requires the computation of large volumes of data that is currently done in data processing centers. Administrations need to have a public custody system for data processing.

We believe that institutions and social organizations should also have access to data for public use. Open data implies interoperability and interconnection of diverse data sources. It also requires designing services that optimize the usage and accessibility of data while ensuring adequate security and privacy. The EC's strategy for data [37] recognizes the need to build new next-generation data-processing infrastructures to reduce technological dependence, since currently European cloud service providers represent only a small share of the cloud market.

Finally, the question of data ownership must be addressed. It should not simply be assumed that citizen-generated data belong to the companies that capture it; this fact has not been actively accepted by society (see [38]). This question acquires particular relevance when the data is to be used for a public purpose. There needs to be a move toward data-sharing models that facilitate the use of data for public purposes, especially in the case of humanitarian emergencies.

\section{Other neglected risks}

To ensure that $\mathrm{AI}$ really contributes to "human welfare" requires a prudent multidisciplinary and ecocentric approach (in harmony with an authentic anthropocentrism that recognizes the essence of the human being and his or her interests) to AI research, as opposed to an excessively techno-optimistic and technocratic approach.

Although the optimistic view of technology predicts a generally positive contribution of $\mathrm{AI}$ to the ability to live a happy and fulfilling life, there are also important risks in this area for individuals, their values, and their personal development. There are important problems associated with the use of this technology such as the alteration of the concept of identity and the nature of human interactions, the difficulty of distinguishing between the real and the virtual, escapism toward virtual worlds, the replacement and deterioration of human bonds, cognitive overload, the loss of meaning and purpose due to being replaced by intelligent machines, and so on. There is a need for a discussion of the potential loss of human values: wisdom, creativity, empathy, affection, social skills, etc.; also be aware of the possibilities of control, manipulation, attack on autonomy, and so on that the field of affective computing opens up, given the susceptibility of humans to emotional influence. Experimental work with social science experts should be promoted with a view to assessing these risks.

The list of high-risk areas mentioned in the document (health, transport, energy, and parts of the public sector such as asylum, migration, border control and justice, social security, and employment services) is not very exhaustive. Applications that may seem harmless a priori [in marketing or financial or insurance services, or in social assistance provided by nongovernmental organizations (NGOs), etc.] may bring about threats to rights if they produce discriminatory, biased results, and so on. Other salient risks are commercial and political manipulation, and intensive coercion and surveillance by governments and large corporations, which can damage social cohesion and contravene democratic principles and human rights. In general, AI requires a proactive approach to risk management, involving continual risk identification and handling.

The Guidelines of the EC's White Paper advocate for individual commitment and self-regulation and consider that regulatory intervention could limit potential innovative capacity; in addition, they advocate the assumption of responsibilities based on the design of the algorithms but not on the social effects and impact of their use; finally, they are in favor of accountability with respect to a series of commitments on technological principles (e.g., transparency) but not on the preservation of values (e.g., equity). All this assumes an AI conceptual framework that is reductionist. The danger is that, by using notions of regulation, self-regulation and ethics in an imprecise and interchangeable way, we are closing the way to the possibility of true spaces in which to define a common standpoint. Al is a technology with a strong transformative potential; it is an opportunity for greater European cohesion if it is viewed from the perspective of promoting the common good of the peoples of Europe. Moreover, the greater the potential of Al, the larger the scale of application. 
The White Paper reduces AI to an instrument of a commercial nature. Responsibility is restricted to the protection of the individual rights of the client or consumer. It has been demonstrated that the value of data and of $\mathrm{AI}$ transcends the concept of technological service and therefore requires mechanisms to ensure proper management of this value.

To use an analogy given in the Zaragoza declaration, $\mathrm{AI}$ has the dimension of a social technology, so the control that is needed over its development and deployment is not simply the quality control of individual products like, say, the quality control of a car. Since its impact is not limited to individual users, the required control is that exercised over infrastructure developments like, say, the planning of the construction of a new bridge. "The design criteria (territorial cohesion and care for environment) are not centered on guaranteeing a specific right to a few individuals but to the mobility within a community." The impact of AI will change society, for which reason AI policy and regulation demands collective debate. Moreover, this debate must be multidisciplinary since, on their own, technologists cannot find the solution to many of the problems that arise with the use of AI. We will need to integrate critical and constructive action to design a society empowered by $\mathrm{AI}$ and that satisfies our idea of a society in which we would wish to live.

\section{Acknowledgments}

David Pastor-Escuredo would like to thank the Innovation and Technology for Development Centre and the Ethic and Digital Revolution Community at Universidad Politecnica de Madrid for collaboration. The work of Simon Pickin was supported in part by the Spanish MINECO-FEDER (FAME) under Grant RTI2018-093608-B-C31 and in part by the Region of Madrid (FORTE-CM) under Grant S2018/TCS-4314.

\section{References}

[1] "White paper on artificial intelligence-A European approach to excellence and trust," Eur. Commission, Brussels, Belgium, White Paper COM(2020) 65 Final, Feb. 2020. Accessed: Feb. 2021. [Online]. Available: https://ec.europa.eu/info/sites/info/files/commissionwhite-paper-artificial-intelligence-feb2020_en.pdf

[2] UN Secretary General Secretary-General, "The road to dignity by 2030: Ending poverty, transforming all lives and protecting the planet," in Synthesis Report of the Secretary-General On the Post-2015 Agenda. New York, NY, USA: United Nations, 2014.
[3] Independent Expert Advisory Group (IEAG) on a Data Revolution for Sustainable Development, "A world that counts-Mobilising the data revolution for sustainable development," IEAG, New York, NY, USA, Tech. Rep., 2014.

[4] Y. Benkler, "Don't let industry write the rules for Al," Nature, vol. 569, no. 7754, pp. 161-162, 2019.

[5] UN Global Pulse, "Big data for development: Challenges \& opportunities," UN Global Pulse, New York, NY, USA, Tech. Rep., 2012.

[6] (2020). UNGP. [Online]. Available: https://www. unglobalpulse.org/discovery/

[7] (2020). UNICEF. [Online]. Available: https://www. unicef.org/innovation/Magicbox

[8] P. J. Zufiria et al., "Identifying seasonal mobility profiles from anonymized and aggregated mobile phone data. Application in food security," PLOS ONE, vol. 13, no. 4, Apr. 2018, Art. no. e0195714.

[9] D. Pastor-Escuredo et al., "Rapid multidimensional impact assessment of floods," Sustainability, vol. 12, no. 10, p. 4246, May 2020.

[10] R. Vinuesa et al., "The role of artificial intelligence in achieving the sustainable development goals," Nature Commun, vol. 11, no. 1, pp. 1-10, 2020.

[11] S. Zuboff, "Big other: Surveillance capitalism and the prospects of an information civilization," J. Inf. Technol., vol. 30, no. 1, pp. 75-89, Mar. 2015.

[12] J. Ziegler, "Report of the special rapporteur on the right to food," UN Hum. Rights Council, Tech. Rep. $\mathrm{A} / \mathrm{HRC} / 7 / 5$, Jan. 2008, pp. 8-10 and 98.

[13] P. Alston, Report of the Special Rapporteur on Extreme Poverty and Human Rights. New York, NY, USA: United Nations General Assembly, 2015.

[14] N. Bostrom, "Strategic implications of openness in Al development," Global Policy, vol. 8, no. 2, pp. 135-148, May 2017.

[15] L. Floridi, "Translating principles into practices of digital ethics: Five risks of being unethical," Philosophy Technol., vol. 32, no. 2, pp. 185-193, Jun. 2019.

[16] J. Morley et al., "From what to how: An initial review of publicly available $\mathrm{Al}$ ethics tools, methods and research to translate principles into practices," Sci. Eng. Ethics, vol. 26, no. 4, pp. 2141-2168, Aug. 2020.

[17] A. Jobin, M. lenca, and E. Vayena, "The global landscape of Al ethics guidelines," Nature Mach. Intell., vol. 1, no. 9, pp. 389-399, Sep. 2019

[18] M. Luengo-Oroz, "Solidarity should be a core ethical principle of Al," Nature Mach. Intell, vol. 1, no. 11, p. 494, 2019. 
[19] L. Vesnic-Alujevic, S. Nascimento, and A. Pólvora, "Societal and ethical impacts of artificial intelligence: Critical notes on European policy frameworks," Telecommun. Policy, vol. 44, no. 6, Jul. 2020, Art. no. 101961.

[20] F. A. Raso et al., "Artificial intelligence \& human rights: Opportunities \& risks," Berkman Klein Center Res. Publication 6-2018, 2018.

[21] R. F. Jørgensen, "What platforms mean when they talk about human rights," Policy Internet, vol. 9, no. 3, pp. 280-296, Sep. 2017.

[22] M. Luengo-Oroz et al., "Artificial intelligence cooperation to support the global response to COVID-19," Nature Mach. Intell., vol. 2, pp. 295-297, May 2020.

[23] F. A. Raso et al., "Artificial intelligence and human rights: Opportunities and risks," Berkman Klein Center Res. Publication 6-2018, 2018.

[24] I. Rahwan et al., "Machine behaviour," Nature, vol. 568, no. 7753, pp. 477-486, 2019.

[25] D. S. Schiff et al., "IEEE 7010: A new standard for assessing the well-being implications of artificial intelligence," 2020, arXiv:2005.06620. [Online]. Available: http://arxiv.org/abs/2005.06620

[26] M. J. Kusner and J. R. Loftus, "The long road to fairer algorithms," Nature, vol. 578, no. 7793, pp. 34-36, Feb. 2020

[27] A. H. R. Commission. (2019). Human Rights and Technology. Discussion Paper. [Online]. Available: https://humanrights.gov.au/our-work/rights-andfreedoms/publications/human-rights-and-technologydiscussion-paper-2019

[28] S. M. Nouri and M. Taqavi, "Cultural conflict in technology transfer to non-industrial communities: A critique of Ihde's ideas," IEEE Technol. Soc. Mag., vol. 39, no. 4, pp. 71-81, Dec. 2020.

[29] P. Fung. (2019). Why Women-Owned Startups Are a Better Bet. World Economic Forum Article. [Online]. Available: https://www.weforum.org/agenda/2019/06/ this-is-why-ai-has-a-gender-problem/

[30] UNESCO. First Draft of the UNESCO Recommendation on Open Science. Accessed: Feb. 2021. [Online]. Available: https://unesdoc.unesco.org/ ark:/48223/pfo000374837

[31] L. Winner, "Do artifacts have politics?" Daedalus, Tech Rep., 1980, pp. 121-136.

[32] B. Miller, "Is technology value-neutral?" Sci, Technol Hum. Values, vol. 46, no. 1, pp. 53-80, 2020.

[33] C. Nodder, Evil by Design: Interaction Design to Lead Us Into Temptation. Hoboken, NJ, USA: Wiley, 2013.
[34] IEEE. (2019). IEEE Global Initiative on Ethics of Autonomous and Intelligent Systems Ethically Aligned Design: A Vision for Prioritizing Human Well-Being With Autonomous and Intelligent Systems v2. [Online]. Available: https://standards.ieee.org/content/dam/ieeestandards/standards/web/documents/other/ead_v2.pdf

[35] (2019). F.Z. Conocimiento. [Online]. Available: https:// www.fundacionzcc.org/estaticos/upload/0/001/1914 pdf

[36] M. Á. Q. Fisac, "Engaging technologies: Criteria for an alternative model of technological development," in Spanish Philosophy of Technology. Cham,

Switzerland: Springer, 2018, pp. 103-123.

[37] European Commission. (Oct. 1, 2020). A European Strategy for Data. Accessed: 2020. [Online]. Available: https://ec.europa.eu/info/strategy/priorities-2019-2024/ europe-fit-digital-age/european-data-strategy

[38] K. Finley. (2017). "Tim Berners-Lee, inventor of the web, plots a radical overhaul of his creation," WIRED. [Online]. Available: https://www.wired.com/2017/04/ tim-berners-lee-inventor-web-plots-radical-overhaulcreation/

Celia Fernández-Aller received the Ph.D. degree in law and technology from the Universidad Nacional de Educación a Distancia (UNED), Madrid, Spain, in 1998.

She was a visiting scholar at UCA El Salvador, San Salvador, El Salvador, and Bristol University, Bristol, U.K. She is currently a Lecturer of Ethical and Legal Aspects with the Department of Computer Systems, Technical University of Madrid, Madrid, Spain. She is one of the experts who will draw up the charter of digital rights for the Spanish government. Her research interests focus on the human rights approach to technology, mainly privacy. She has several papers and books related to her area of interest.

Arturo Fernández de Velasco received the master's degree in telecommunication engineering from Universidad Politécnica de Madrid (UPM), Madrid, Spain, in 2001

Since 2001, he has been working as a Network Engineer for several service providers in Spain. He serves on the Board of Directors of Ongawa, a nongovernmental organization which has a mission of bringing technology for human development, where he has contributed to implement several ICT4D projects (Information and Communications Technology for Development). He is currently working in the area of network virtualization, developing data centers for $5 \mathrm{G}$ network infrastructures. 
Ángeles Manjarrés is currently a Lecturer with the Department of Artificial Intelligence, Universidad Nacional de Educación a Distancia (UNED), Madrid, Spain, the Spanish national distance-learning university. Her research is focused on the field of ontologies and educational recommender systems, in e-learning and educational robotics. She has participated in national, European, and international research projects, and in educational innovation projects integrating service-learning methodology into artificial intelligence studies.

Ms. Manjarres is a member of the UNED ServiceLearning Department Management Team, the UNED Research Ethics Committee, and the Education for Development Group EDETIC, affiliated to the Innovation and Technology for Development Center, Technical University of Madrid, Madrid.

David Pastor-Escuredo received the Ph.D. degree in artificial intelligence and complex systems from Universidad Politécnica de Madrid (UPM), Madrid, Spain, in 2015

He was a pioneer collaborator of several United Nations agencies (UNGP, WFP, and UNHCR) in Al and Data for Sustainable Development Goals. $\mathrm{He}$ has led digital innovation projects at Centro de Innovación en Tecnología para el Desarrollo de la Universidad Politécnica de Madrid (itdUPM) managing partnerships with MIT research centers and labs. He is currently a Consultant for UNICEF. $\mathrm{He}$ works in the Al for Healthcare within the program Catalyst Europe EIT Health-MIT.

Dr. Pastor-Escuredo is a member of the Ethics and Digital Revolution Group of itdUPM and "El Dia Despues" cities community. He was awarded by EIT Health as the Best Catalyst Project 2020.

Simon Pickin received the B.Sc. degree in mathematics from the University of Sussex, Brighton, U.K., in 1982, the CASM (Cambridge Part III) degree in mathematics from the University of Cambridge. Cambridge, U.K., in 1986, the M.Sc. degree from
Kings College, University of London, London, U.K., in 1987, the second M.Sc. degree in computing from Imperial College, University of London, London, in 1988, and the Ph.D. degree from the Universite de Rennes, Rennes, France, in 2003.

He was a researcher in public and private sectors in France and Spain for the last 30 years. He is currently a Lecturer with the Computing Faculty, Complutense University of Madrid, Madrid, Spain. His research interests focus on formal methods and testing, as well as on ICT4D.

Jesús Salgado Criado received the Electronic Engineer degree from Universidad Pontificia Comillas, Madrid, Spain, in 1988 and the M.B.A. degree from the IESE Business School, Barcelona, Spain, in 1996.

He has worked as the project director for various technology organisations and has co-founded several initiatives in the IT space. He is currently an Associate Professor with the Department of Business Administration, Universidad Politécnica de Madrid, Madrid. His current research focuses on algorithm auditability and societal risk management and regulation of $\mathrm{Al}$ applications.

Txetxu Ausín is currently a tenured Scientist at the Institute of Philosophy, CSIC (Spanish National Research Council), Madrid, Spain, and the Director of the Applied Ethics Group (GEA). He is also an Invited Professor with several universities and a Researcher with the Institute for Democratic Governance, GLOBERNANCE, Donostia, Spain. His research areas include public ethics, bioethics, human rights, and philosophy of disruptive technologies.

Direct questions and comments about this article to Celia Fernández-Aller, ETSISI, 28031 Madrid, Spain; mariacelia.fernandez@upm.es. 